\title{
Personal Relative Deprivation and Reward-Based Eating: Two Exploratory Studies
}

\author{
William J. Skylark* Mitchell J. Callan ${ }^{\dagger}$
}

April 26, 2021

\begin{abstract}
Personal relative deprivation (PRD) is the belief that one is worse off than other people who are like oneself, in a way that seems unfair and which induces resentment. Previous work suggests that PRD may be associated with increased preference for energy dense/unhealthy foods, and more broadly that PRD entails an increased focus on gaining rewards even if these may come with longer-term costs. We report two studies that build on this research by examining the correlation between PRD and self-reported reward-based eating drives (RED). In both studies, higher PRD was associated with greater RED, whereas other indicators of objective and subjective status had little or no meaningful association with RED. RED was also positively associated with negative affect (examined in Study 1) and low self esteem (examined in Study 2), and negatively associated with age. In multiple regression analyses in which all predictors were entered simultaneously, negative affect, self esteem and age continued to predicted RED over and above the effects of other variables, but there was less indication that PRD provided unique predictive power; in Study 1, there was a modest positive effect of PRD but the $95 \%$ CIs were quite wide and included zero; in Study 2, which used a larger sample and produced a more precise parameter estimate, there was a positive effect of PRD with $95 \%$ CIs that just included zero when conventional OLS regression was used, and which just excluded zero when robust regression was used. Taken together, the data suggest an association between relative deprivation and reward-based eating which could form the basis for productive future inquiry.
\end{abstract}

Personal Relative Deprivation (PRD; sometimes also called Individual Relative Deprivation) refers to the resentment that arises when a person feels that they are deprived relative to other people who are like them (e.g., Smith et al., 2012). PRD has been associated with a range of socio-economic outcomes and behaviours, including physical and mental health (e.g., Callan et al., 2015; Mishra \& Carleton, 2015; Smith et al., 2020), aggression (Greitemeyer \& Sagioglou, 2019) and consumer spending preferences (e.g., Kim et al., 2017). PRD is related to, but distinct from, subjective socioeconomic status (SSS); the latter is typically measured by asking people where their income, education, and employment puts them in a national hierarchy of status (e.g., Adler et al., 2000; Skylark \& Baron-Cohen, 2017). Like SSS, PRD concerns subjective relative status, but PRD differs in that it (a) focuses on self-selected peers (people "like me") rather than national or regional hierarchies, and (b) PRD captures the sense of injustice resulting from the perception that relative status is unfair.

One conceptualization of the effects of PRD is that it entails a focus on behaviours that will bring an immediate reward, perhaps at the cost of longer-term outcomes

\footnotetext{
${ }^{*}$ Department of Psychology, University of Cambridge. wjm22@cam.ac.uk.

${ }^{\dagger}$ Department of Psychology, University of Bath. m.j.callan@bath.ac.uk. This work was supported by Leverhulme Trust grant RPG-2013-148.
}

(e.g., Callan et al., 2008; 2011; Kim et al., 2017; Tabir et al., 2015). Thus, researchers have reported that PRD is positively associated with greater willingness to choose small, immediate monetary gains over larger, delayed ones (Callan et al., 2011), an increased willingness to gamble (e.g., Callan et al., 2008; Mishra \& Novakowski, 2016), increased materialism (Kim et al., 2017) and reduced willingness to incur a cost to oneself in order to help others (Callan et al., 2017; Zhang et al., 2016) ${ }^{1}$

Here we report two studies that examine a possible association between PRD and another behaviour that yields immediate gratification, namely reward-based eating. The consumption of palatable foods offers a shortterm reward that can come with long-term costs in the form of health problems (e.g., Gearhardt et al., 2011). Many studies have examined the links between objective socioeconomic status and eating behaviours (e.g., Drewnowski \& Specter, 2004). More recently, researchers have examined links between eating behaviour and subjective status. For example, Bratanova et al. (2016) report that calorie consumption is increased for people who are led to believe that they are relatively poorly-off, and Cheon and Hong (2017) report that having people consider the difference between their own social status and that of people at the very top of society (i.e., who

\footnotetext{
${ }^{1}$ In some circumstances, relative deprivation can also lead to more long-terms attempt at self-improvement; e.g., Zoogah (2010).
} 
were encouraged to consider themselves as deprived) led to increased calorie consumption compared with participants who contrasted themselves with people at the very bottom of society (i.e., who considered themselves relatively affluent). In somewhat related work, Pavela et al. (2017) found no effect on food intake of manipulating social status by assigning participants to be a "leader" or a "follower", and Cardel and colleagues (2016, 2020) report ambivalent results when subjective status was manipulated via a rigged game of monopoly (in particular, the effects may be moderated by gender). And, in a pilot study, Wijayatunga et al. (2019) found that lower SSS was associated with higher energy balance and less ability to compensate for eating a large lunch.

Of particular relevance to the current work, Sim et al. (2018) have reported that self-reported background levels of PRD [assessed via Callan et al.'s (2011) Personal Relative Deprivation Scale] were positively correlated with portion selection in both a computerized task and when participants served themselves a meal (the analysis controlled for gender and appetite ratings from the start of the session, and excluded participants who were actively dieting). In a second experiment these authors experimentally manipulated PRD by having participants imagine that they were to receive a smaller bonus than some of their (hypothetical) co-workers (c.f. a control group where the bonuses were the same for everyone), and found that this entailed the selection of larger portions in a computerized task; again, this analysis controlled for gender and appetite, and the association remained after controlling for negative mood.

The two studies reported below complement the foregoing studies by examining whether PRD and SSS are associated with self-reported reward-based eating drives, assessed via Epel et al.'s (2014) Reward-based Eating Drives (RED) scale. This scale gauges individual differences in the tendency for eating to be driven by rewardseeking, by probing three facets of eating behaviour that are often reported by people who experience persistent weight gain: a feeling of lacking control over eating; eating rapidly without satiation; and being preoccupied by food. Epel et al. found that scores on the RED correlated with body mass index (BMI) and "predicted earlier onset of obesity, greater weight fluctuations, and greater overall weight gain over eight years" (p.1). Subsequent work found that the effect of a mindfulness-based diet and exercise intervention on weight loss was mediated by a reduction scores on the RED scale (Mason et al., 2016). The potential association between relative deprivation and reward-based eating may therefore have implications for long-term health outcomes.

\section{Method}

We conducted two on-line studies in which participants indicated their feelings of personal relative deprivation, reward-based eating drives, objective status indicators (income and education), and subjective socio-economic status. In Study 1, participants also indicated their experience of negative affect; in Study 2, this measure was replaced by self-esteem. Although we expected PRD to be associated with RED, both studies were exploratory. The data were collected in 2016 and 2017.

\section{Materials}

We used the following measures/items:

- RED: The 9-item Reward-Based Eating Drive Scale (Epel et al., 2014) with responses coded 1-5.

- PRD: The 5-item Personal Relative Deprivation Scale (Callan et al., 2011), with responses coded 16.

- SSS: Participants indicated their subjective socioeconomic status via a cartoon ladder representing where people stand in the social class hierarchy of the United States (e.g., Skylark \& Baron-Cohen, 2017).

- Negative Affect: In Study 1, participants completed the negative affect component of the Positive and Negative Affect Scale (PANAS; Watson et al., 1988), with responses coded $1-5$.

- Self-Esteem: In Study 2, participants completed Rosenberg's (1965) self-esteem scale, with responses coded $1-4$.

Participants also reported their annual household income (before taxes) with response options "Less than $\$ 10,000 ", " \$ 10,001$ to $\$ 20,000 ", " \$ 20,001$ to $\$ 30,000 "$ and so on in $\$ 10,000$ increments, with the final option being "More than $\$ 150,000 "$. On the next page participants were asked: "Including you, how many adults are in your household?" and "How many children are in your household?" (these questions were answered via text-boxes that required a numeric response). On the same page participants were then asked: "What is your highest level of educational attainment?" with response options: "did not finish high school", "high school graduation", "college graduation", "postgraduate degree". Then: "Are you:" with response options "Male" and "Female", followed by "What is your age?" with responses provided by a numeric slider ranging from 0 to 100 .

\section{Design and Procedure}

In Study 1, after the initial information sheet participants completed the PRD, RED, SSS and Negative Affect measures in random order, followed by the demographic questions and finally a debriefing page. All questions required a response before the participant could progress to the next page, but a coding error for the SSS ladder meant that participants could provide more than one response (select more than one rung) or skip that question.

In Study 2, participants completed the PRD, RED, SSS and Self Esteem measures in random order, followed by the demographic questions and debriefing. All questions required a response.

PDFs of both questionnaires as included in the Supplementary Materials (https://osf.io/zxc7v/). 


\section{Participants}

Participants were recruited via Amazon's Mechanical Turk (MTurk). We requested participants with a "HIT Approval Rate" greater than or equal to $98 \%$ and who had completed 1000 or more tasks on the platform. Following the precedent of previous work, we discarded without analysis responses from participants who did not answer all questions (or, for Study 1, who selected more than one rung of the SSS ladder), who indicated an age less than 18 , or whose IP address occurred earlier in the data set (in the case of overlapping timestamps, both instances were excluded). Our initial launch of Study 1 had technical problems which prevented people from progressing through the task; these respondents were discarded without analysis, but their IP addresses were used during duplicate screening to ensure that included participants were taking part for the first time; likewise, IP addresses in Study 1 were used when checking for duplicates in Study 2. Finally, for Study 2 we excluded participants who failed the attention check $(\mathrm{N}=28)$.

After applying these criteria we had $N=354$ in Study 1 and $N=816$ in Study 2. Our intention was to recruit participants from the USA, but in Study 1 we did not include this as a criterion when requesting participants from the platform. After collecting and analysing the data, we realised that we could use IP addresses to screen non-US participants; we used the maxmind function from the rgeolocate package (Keyes et al., 2020) for R (R Core Team, 2020) to identify the (probable) location of each participant; of the 354 participants, 329 were indicated to be from the USA. For Study 2, we did request US-based participants from the recruitment platform but applying the IP-screening tool indicated that 799 of the 816 were from the USA.

Our preference is to focus on the results from participants from the United States, especially because it is not clear how meaningful/interpretable the objective and subjective social status indicators are for participants from elsewhere. Nonetheless, for the sake of full disclosure we report the results of the larger "All locations" data from each study in the Appendix.

Table 1 shows the sample characteristics for Studies 1 and 2. For the annual household income data, we used Parker and Fenwick's (1983) median-based Pareto estimator to compute the value for the top category (see e.g., Matthews et al., 2016). Some researchers (e.g., Boyce et al., 2010) divide annual household income by household size $\left(N_{\text {adults }}+0.5 * N_{\text {children }}\right)$ to better capture spending power, so we computed this measure (which we label Adjusted Income), too. (The table reports Cronbach's $\alpha$ to indicate internal consistency; we attempted to compute $\omega_{h}$ using the psych package for R (Revelle, 2020), but encountered warnings.)

\section{Results and Discussion}

The data and analysis script are included in the Supplementary Materials (https://osf.io/zxc7v/).

Tables 2 and 3 shows the correlation matrices for 
Studies 1 and 2, respectively; in each case, we report both Pearson's and Kendall's correlations (Signorell et al., 2021), and the results from the two approaches are similar. (We conducted both types of analysis because some of the measures are not normally distributed, although with such large sample sizes this is unlikely to be critical.)

In both studies, people with higher personal relative deprivation reported greater reward-based eating drives. RED was also greater among younger participants and, as might be expected, stronger for participants who reported more negative affect (Study 1 ) and lower self esteem (Study 2). There is also some indication that RED was more pronounced among women than men, but this only emerges in Study 2, and then only when Pearson's correlation is used. There is little indication that RED is meaningfully associated with objective indicators of socio-economic status, or with subjective status (SSS). In both studies participants reporting higher PRD also report more negative affect (Study 1) and lower self-esteem (Study 2); this is unsurprising given the affective component of relative deprivation (e.g., resentment) and the fact that "doing worse" than other people who are like you is semantically associated with some aspects of self esteem (e.g., the scale item "I feel that I am a person of worth, at least on an equal plane with others"). As in previous work (Callan et al., 2015), PRD was lower among older participants.

We conducted regression analyses to evaluate the contribution of each predictor after controlling for the others. To check robustness/generality, we examined 6 different models which differed in their treatment of objective socio-economic indicators, because in previous work researchers have adopted different approaches to these variables (e.g., Callan et al., 2017; Skylark \& BaronCOhen, 2017). Regarding income: for Models 1 and 6 we used mean-centred adjusted household income (ADJ); for Model 2 we used mean-centred household income (INC); for Model 3 we used mean-centred $\log _{10}$-transformed adjusted household income $(\log (A D J))$; for Model 4 we used mean-centred income category responses (i.e., we coded the income bin the participant selected from 1 to 16 ; this variable was labelled Int INC); and for Model 5 we averaged z-scored household income and education to get an overall indication of socio-economic status (labelled SES), which was itself z-scored. Regarding education: for Models $1-4$ it was treated as an interval-scale variable, and z-scored; for Model 6 it was treated as a factor (with weighted effect coding, via the wec package for $\mathrm{R}$ (Grotenhuis et al., 2016, package version 0.1-4), with "Did not finish high school" as the omitted category. Finally, we fit all models using both ordinary least squares regression (OLS) and robust regression using the Imrob function from the robustbase package for $\mathrm{R}$ (Maechler et al., 2020), with the recommended "KS2014" setting. As in other work (e.g., Skylark et al., 2020, 2021), our goal in trying these various analyses was to ensure that our inferences were not the result of a particular set of analytic decisions. For all regression analyses, RED, PRD, Negative Affect and Self Esteem were z-scored, SSS was meancentred, gender was coded -0.5 for male, +0.5 for female, and age was mean-centred and expressed in decades (so the regression coefficient indicates the effect of being 10 years older).

The estimates of the regression coefficients and their 95\% confidence intervals are shown in Figure $2^{2}$ Reassuringly, the results are generally very consistent across regression models (i.e., the treatment of socio-economic indicators, and the use of OLS vs robust regression, makes little difference). In both studies, there is a negative effect of age. Study 1 finds a strong positive effect of negative affect (people experiencing less negative affect report lower reward-based eating drives), and Study 2 finds a strong negative effect of self-esteem (people with higher self-esteem report less reward-based eating drives). Study 2 finds that women report stronger RED than men, but this did not emerge in Study 1 . There is generally little indication that the objective socio-economic indicators predict RED, although the log-transformed adjusted income measure coefficient has $\mathrm{Cls}$ that exclude zero in Study 1 (but not Study 2), suggesting that this variable is positively associated with reward-based eating drives.

Of most relevance to the aims of the research, the regression coefficients for PRD are positive but the confidence intervals typically span zero; for Study 2, the robust regression produces estimates for all 6 models that are just "significant", but the confidence intervals only just exclude zero. Because Study 1 controls for Negative Affect and Study 2 controls for Self Esteem, we cannot readily combine the two sets of data.

Finally, as mentioned above we ran the same analyses including participants whose IP address indicated that they were outside the US (see Appendix). We do not dwell on these results, but only that they are similar to those using the US-only sample. One difference is that in Study 1, the regression coefficient for PRD has 95\% $\mathrm{Cls}$ that just exclude zero, suggesting an effect over and above that of the other predictors; for Study 2, the pattern of regression coefficients for PRD mimics that for the US-only sample.

\section{Conclusions}

These studies provide an initial exploration of a possible link between personal relative deprivation and rewardbased eating. Consistent with previous work finding an association between PRD and food consumption (Sim et al., 2018) we found that higher PRD was associated with stronger self-reported reward-based eating drives. However, we found little indication that PRD substantially predicts RED over and above general negative affect and self esteem (although the confidence intervals for the effect of PRD are quite wide and more highly-powered studies might reveal a meaningful effect). Related to this, the causal links between these constructs remains unclear. For example, one interpretation of our correlation and

\footnotetext{
${ }^{2}$ For Model 6, weighted-effects coding was used with Did not finish high school as the omitted category (because there were very few respondents in this category); the SCHOOL, COLLEGE, and POSTGRAD[UATE] coefficients indicate the effects for these levels of education vs the population average.
} 
Table 2: Study 1 Correlation Matrices

\begin{tabular}{|c|c|c|c|c|c|c|c|c|}
\hline & \multicolumn{8}{|c|}{ Pearson correlations } \\
\hline & RED & $\mathrm{AFF}$ & PRD & SSS & ADJ & INC & EDU & AGE \\
\hline \multirow[t]{2}{*}{$\mathrm{AFF}$} & $.44(<.001)$ & & & & & & & \\
\hline & {$[.35, .52]$} & & & & & & & \\
\hline \multirow[t]{2}{*}{ PRD } & $.25(<.001)$ & $.39(<.001)$ & & & & & & \\
\hline & {$[.14, .35]$} & {$[.29, .48]$} & & & & & & \\
\hline \multirow[t]{2}{*}{ SSS } & $-.10(.061)$ & $-.19(.001)$ & $-.49(<.001)$ & & & & & \\
\hline & {$[-.21, .00]$} & {$[-.29,-.08]$} & {$[-.57,-.40]$} & & & & & \\
\hline \multirow[t]{2}{*}{ ADJ } & $.01(.856)$ & $-.07(.200)$ & $-.29(<.001)$ & $.49(<.001)$ & & & & \\
\hline & {$[-.10, .12]$} & {$[-.18, .04]$} & {$[-.38,-.18]$} & {$[.41, .57]$} & & & & \\
\hline \multirow[t]{2}{*}{ INC } & $.00(.961)$ & $-.08(.131)$ & $-.35(<.001)$ & $.54(<.001)$ & $.76(<.001)$ & & & \\
\hline & {$[-.11, .11]$} & {$[-.19, .02]$} & {$[-.44,-.25]$} & {$[.46, .61]$} & {$[.71, .80]$} & & & \\
\hline \multirow[t]{2}{*}{$\mathrm{EDU}$} & $-.04(.515)$ & $-.06(.267)$ & $-.17(.002)$ & $.34(<.001)$ & $.37(<.001)$ & $.32(<.001)$ & & \\
\hline & {$[-.14, .07]$} & {$[-.17, .05]$} & {$[-.27,-.06]$} & {$[.24, .43]$} & {$[.27, .46]$} & {$[.21, .41]$} & & \\
\hline \multirow[t]{2}{*}{$\mathrm{AGE}$} & $-.26(<.001)$ & $-.23(<.001)$ & $-.20(<.001)$ & $.13(.020)$ & $.08(.137)$ & $.03(.568)$ & $.15(.008)$ & \\
\hline & {$[-.36,-.15]$} & {$[-.33,-.13]$} & {$[-.30,-.09]$} & {$[.02, .23]$} & {$[-.03, .19]$} & {$[-.08, .14]$} & {$[.04, .25]$} & \\
\hline \multirow[t]{4}{*}{ GEN } & $-.07(.223)$ & $-.01(.822)$ & $.01(.897)$ & $-.08(.124)$ & $-.10(.078)$ & $-.07(.190)$ & $.01(.908)$ & $.17(.002)$ \\
\hline & {$[-.17, .04]$} & {$[-.12, .10]$} & {$[-.10, .12]$} & {$[-.19, .02]$} & {$[-.20, .01]$} & {$[-.18, .04]$} & {$[-.10, .11]$} & {$[.06, .27]$} \\
\hline & \multicolumn{8}{|c|}{ Kendall correlations } \\
\hline & RED & $\mathrm{AFF}$ & PRD & SSS & ADJ & INC & EDU & AGE \\
\hline \multirow[t]{2}{*}{$\mathrm{AFF}$} & $.31(<.001)$ & & & & & & & \\
\hline & {$[.23, .38]$} & & & & & & & \\
\hline \multirow[t]{2}{*}{ PRD } & $.18(<.001)$ & $.32(<.001)$ & & & & & & \\
\hline & {$[.10, .26]$} & {$[.25, .39]$} & & & & & & \\
\hline \multirow[t]{2}{*}{ SSS } & $-.06(.160)$ & $-.17(<.001)$ & $-.37(<.001)$ & & & & & \\
\hline & {$[-.14, .03]$} & {$[-.25,-.09]$} & {$[-.44,-.30]$} & & & & & \\
\hline \multirow[t]{2}{*}{ ADJ } & $.04(.338)$ & $-.06(.129)$ & $-.24(<.001)$ & $.43(<.001)$ & & & & \\
\hline & {$[-.04, .11]$} & {$[-.14, .02]$} & {$[-.31,-.17]$} & {$[.37, .49]$} & & & & \\
\hline \multirow[t]{2}{*}{ INC } & $.03(.503)$ & $-.07(.066)$ & $-.26(<.001)$ & $.47(<.001)$ & $.61(<.001)$ & & & \\
\hline & {$[-.05, .10]$} & {$[-.15, .00]$} & {$[-.33,-.19]$} & {$[.40, .54]$} & {$[.56, .66]$} & & & \\
\hline \multirow[t]{2}{*}{$\mathrm{EDU}$} & $-.01(.751)$ & $-.04(.364)$ & $-.13(.004)$ & $.29(<.001)$ & $.30(<.001)$ & $.27(<.001)$ & & \\
\hline & {$[-.10, .07]$} & {$[-.13, .05]$} & {$[-.21,-.04]$} & {$[.21, .37]$} & {$[.23, .38]$} & {$[.19, .35]$} & & \\
\hline \multirow[t]{2}{*}{ AGE } & $-.17(<.001)$ & $-.19(<.001)$ & $-.12(.002)$ & $.08(.055)$ & $.07(.078)$ & $.03(.406)$ & $.11(.011)$ & \\
\hline & {$[-.24,-.10]$} & {$[-.27,-.11]$} & {$[-.19,-.05]$} & {$[-.00, .16]$} & {$[-.01, .14]$} & {$[-.04, . .11]$} & {$[.02, .20]$} & \\
\hline \multirow[t]{2}{*}{ GEN } & $-.07(.133)$ & $.03(.545)$ & $-.00(.988)$ & $-.07(.167)$ & $-.08(.079)$ & $-.07(.138)$ & $.01(.793)$ & $.15(.001)$ \\
\hline & {$[-.16, .02]$} & {$[-.06, .12]$} & {$[-.09, .09]$} & {$[-.16, .03]$} & {$[-.17, .01]$} & {$[-.16, .02]$} & {$[-.09, .12]$} & {$[.06, .23]$} \\
\hline
\end{tabular}

$p$-values are shown in parentheses; the $95 \% \mathrm{CI}$ is shown below each estimate. GEN = Gender; other abbreviations are the same as for Table 1 . 
Table 3: Study 2 Correlation Matrices

\begin{tabular}{|c|c|c|c|c|c|c|c|c|}
\hline \multirow[b]{3}{*}{ EST } & \multicolumn{8}{|c|}{ Pearson correlations } \\
\hline & RED & $\mathrm{EST}$ & PRD & SSS & ADJ & INC & EDU & AGE \\
\hline & $\begin{array}{c}-.30(<.001) \\
{[-.36,-.23]}\end{array}$ & & & & & & & \\
\hline \multirow[t]{2}{*}{$\mathrm{PRD}$} & $.18(<.001)$ & $-.54(<.001)$ & & & & & & \\
\hline & {$[.11, .25]$} & {$[-.59,-.49]$} & & & & & & \\
\hline \multirow[t]{2}{*}{ SSS } & $-.04(.273)$ & $.38(<.001)$ & $-.47(<.001)$ & & & & & \\
\hline & {$[-.11, .03]$} & {$[.32, .44]$} & {$[-.52,-.41]$} & & & & & \\
\hline \multirow[t]{2}{*}{ ADJ } & $-.03(.340)$ & $.20(<.001)$ & $-.25(<.001)$ & $.52(<.001)$ & & & & \\
\hline & {$[-.10, .04]$} & {$[.14, .27]$} & {$[-.32,-.19]$} & {$[.47, .57]$} & & & & \\
\hline \multirow[t]{2}{*}{ INC } & $-.01(.781)$ & $.26(<.001)$ & $-.34(<.001)$ & $.62(<.001)$ & $.72(<.001)$ & & & \\
\hline & {$[-.08, .06]$} & {$[.19, .32]$} & {$[-.40,-.28]$} & {$[.57, .66]$} & {$[.68, .75]$} & & & \\
\hline \multirow[t]{2}{*}{ EDU } & $.02(.574)$ & $.12(.001)$ & $-.13(<.001)$ & $.39(<.001)$ & $.33(<.001)$ & $.32(<.001)$ & & \\
\hline & {$[-.05, .09]$} & {$[.05, .19]$} & {$[-.20,-.06]$} & {$[.33, .45]$} & {$[.27, .39]$} & {$[.26, .38]$} & & \\
\hline \multirow[t]{2}{*}{$\mathrm{AGE}$} & $-.15(<.001)$ & $.18(<.001)$ & $-.11(.002)$ & $.06(.080)$ & $.10(.003)$ & $.08(.028)$ & $.05(.144)$ & \\
\hline & {$[-.22,-.08]$} & {$[.11, .25]$} & {$[-.18,-.04]$} & {$[-.01, .13]$} & {$[.04, .17]$} & {$[.01, .15]$} & {$[-.02, .12]$} & \\
\hline \multirow[t]{4}{*}{ GEN } & $.08(.018)$ & $-.03(.397)$ & $-.02(.485)$ & $.01(.840)$ & $-.06(.072)$ & $.02(.499)$ & $-.00(.972)$ & $.15(<.001)$ \\
\hline & {$[.01, .15]$} & {$[-.10, .04]$} & {$[-.09, .04]$} & {$[-.06, .08]$} & {$[-.13, .01]$} & {$[-.05, .09]$} & {$[-.07, .07]$} & {$[.08, .21]$} \\
\hline & \multicolumn{8}{|c|}{ Kendall correlations } \\
\hline & RED & $\mathrm{EST}$ & PRD & SSS & ADJ & INC & EDU & $\mathrm{AGE}$ \\
\hline $\mathrm{EST}$ & $\begin{array}{c}-.23(<.001) \\
{[-.28,-.18]}\end{array}$ & & & & & & & \\
\hline \multirow[t]{2}{*}{ PRD } & $.14(<.001)$ & $-.40(<.001)$ & & & & & & \\
\hline & {$[.09, .19]$} & {$[-.45,-.36]$} & & & & & & \\
\hline \multirow[t]{2}{*}{ SSS } & $-.00(.911)$ & $.27(<.001)$ & $-.36(<.001)$ & & & & & \\
\hline & {$[-.05, .05]$} & {$[.22, .32]$} & {$[-.40,-.31]$} & & & & & \\
\hline \multirow[t]{2}{*}{ ADJ } & $-.03(.279)$ & $.17(<.001)$ & $-.19(<.001)$ & $.42(<.001)$ & & & & \\
\hline & {$[-.08, .02]$} & {$[.12, .21]$} & {$[-.24,-.15]$} & {$[.37, .46]$} & & & & \\
\hline \multirow[t]{2}{*}{ INC } & $-.01(.790)$ & $.20(<.001)$ & $-.24(<.001)$ & $.51(<.001)$ & $.61(<.001)$ & & & \\
\hline & {$[-.06, .04]$} & {$[.15, .25]$} & {$[-.29,-.20]$} & {$[.47, .55]$} & & & & \\
\hline \multirow[t]{2}{*}{$\mathrm{EDU}$} & $.03(.316)$ & $.09(.001)$ & $-.11(<.001)$ & $.33(<.001)$ & $.27(<.001)$ & $.26(<.001)$ & & \\
\hline & {$[-.03, .08]$} & {$[.04, .15]$} & {$[-.16,-.05]$} & {$[.28, .38]$} & {$[.22, .32]$} & {$[.21, .32]$} & & \\
\hline \multirow[t]{2}{*}{ AGE } & $-.09(<.001)$ & $.12(<.001)$ & $-.07(.003)$ & $.05(.057)$ & $.11(<.001)$ & $.10(<.001)$ & $.06(.035)$ & \\
\hline & {$[-.14,-.05]$} & {$[.08, .17]$} & {$[-.12,-.03]$} & {$[-.00, .10]$} & {$[.07, .16]$} & {$[.05, .14]$} & {$[.01, .11]$} & \\
\hline \multirow[t]{2}{*}{ GEN } & $.05(.071)$ & $-.03(.376)$ & $-.02(.506)$ & $-.00(.992)$ & $-.05(.075)$ & $.02(.598)$ & $.00(.901)$ & $.12(<.001)$ \\
\hline & {$[-.01, .11]$} & {$[-.08, .03]$} & {$[-.08, .04]$} & {$[-.06, .06]$} & {$[-.11, .00]$} & {$[-.04, .08]$} & {$[-.06, .07]$} & {$[.06, .17]$} \\
\hline
\end{tabular}

$p$-values are shown in parentheses; the $95 \% \mathrm{CI}$ is shown below each estimate. GEN = Gender; other abbreviations are the same as for Table 1 . 
Study 1: US (OLS)

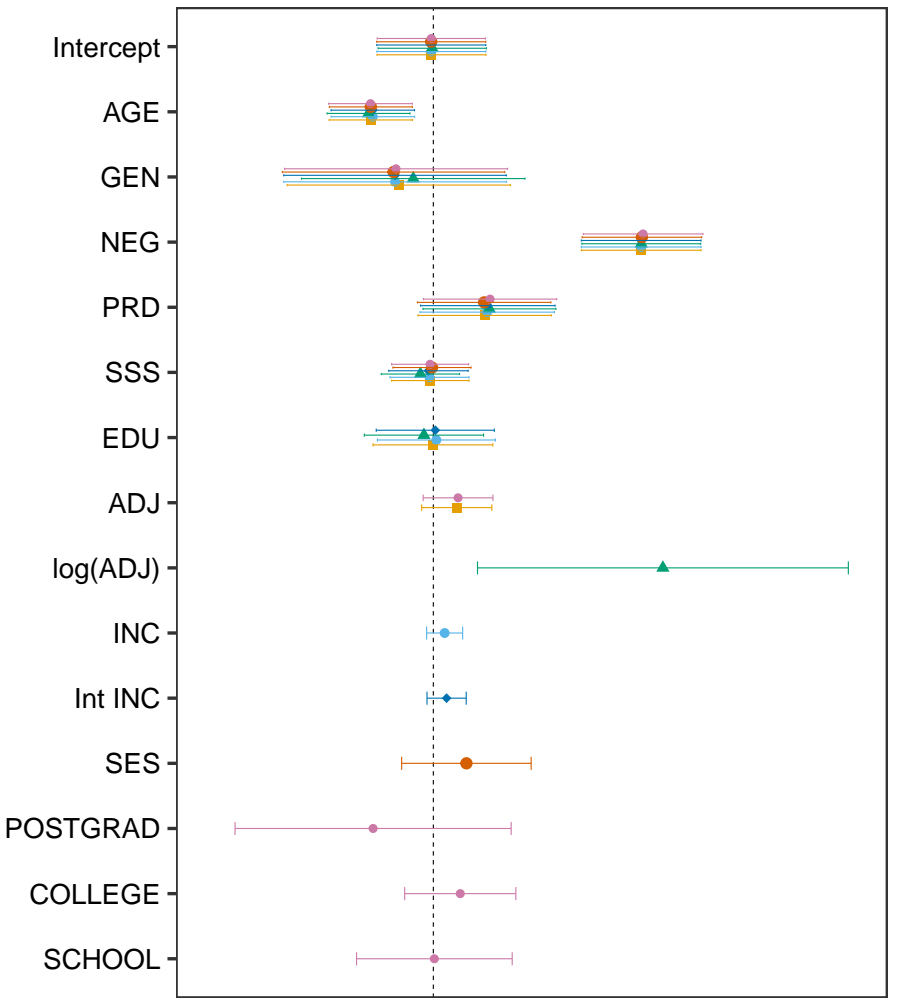

Study 2: US (OLS)

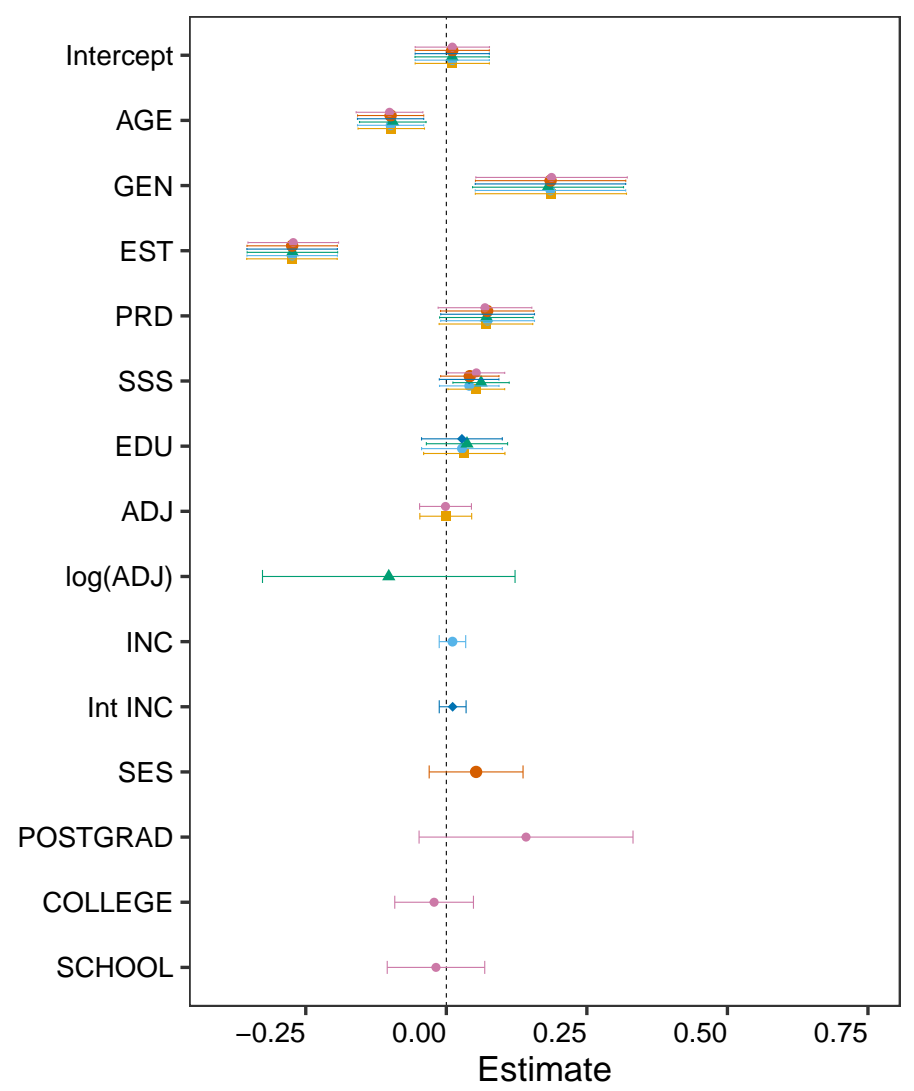

Study 1: US (Robust)

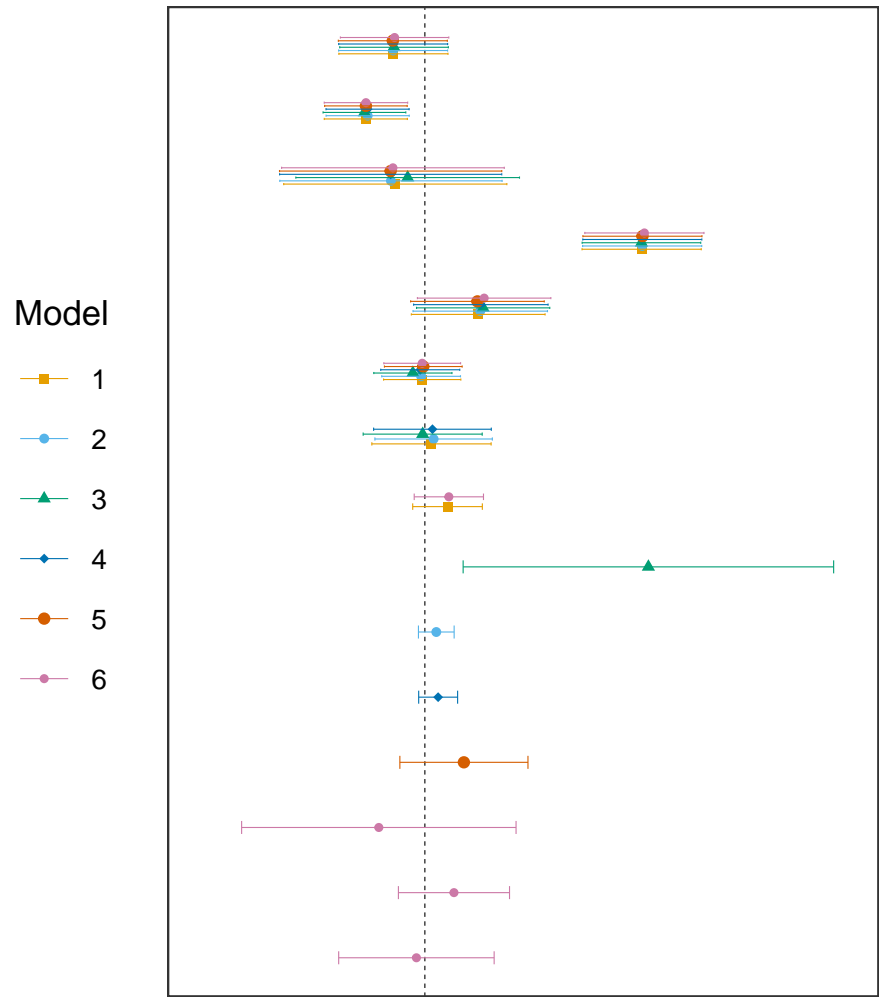

\section{Study 2: US (Robust)}

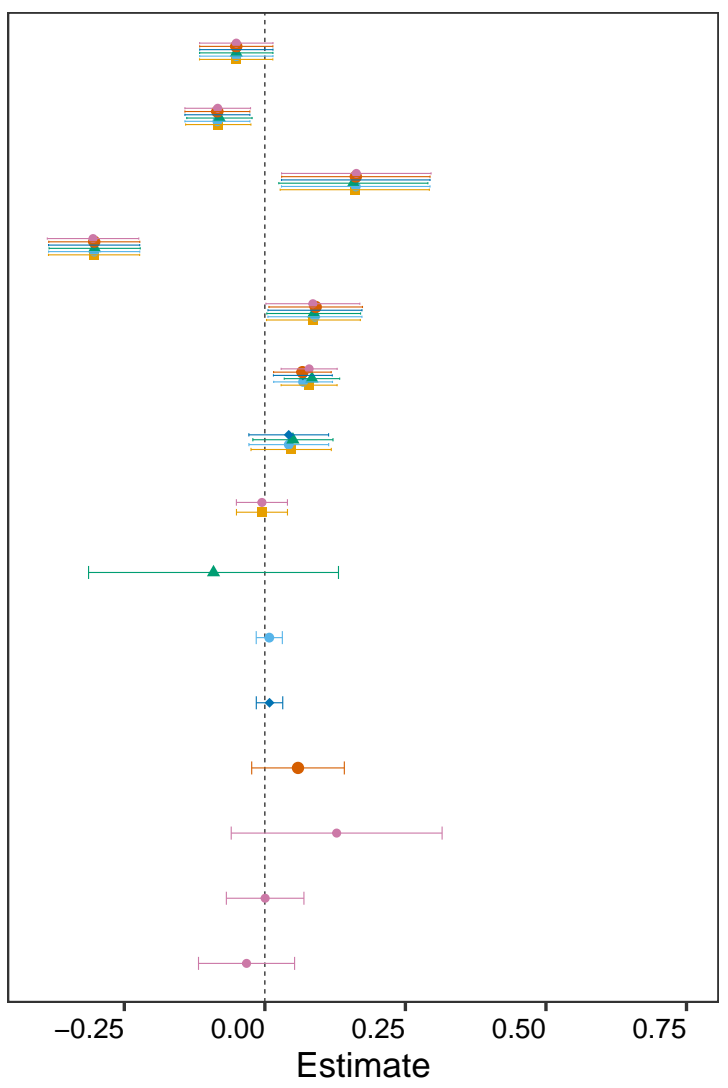

Figure 1: Regression coefficients. See main text for explanation of the predictor abbreviations and models. 
regression analyses is that negative affect and low self esteem mediate the link between PRD and RED. We can envisage the belief that one is deprived of outcomes enjoyed by one's immediate peers leading to a sense of worthlessness and frustration that in turn drive a desire for immediate reward/pleasurable experiences. But other causal relations are obviously also feasible, and only by conducting more research will the pattern become clearer. Ideally, such research will involve longitudinal studies using nationally-representative samples, and will probe a range of eating behaviours and outcomes - for example, dieting, disordered eating, and physical/mental health. The two exploratory studies reported here provide a starting point for such research.

\section{References}

Adler, N. E., Epel, E. S., Castellazzo, G., \& Ickovics, J. R. (2000). Relationship of subjective and objective social status with psychological and physiological functioning: Preliminary data in healthy white women. Health Psychology, 19(6), 586-592. https: //doi.org/10.1037/0278-6133.19.6.586

Boyce, C. J., Brown, G. D. A., \& Moore, S. C. (2010). Money and happiness: Rank of income, not income, affects life satisfaction. Psychological Science, 21(4), 471--475. https://doi.org/10.1177/ 0956797610362671

Bratanova, B., Loughnan, S., Klein, O., Claassen, A., \& Wood, R. (2016). Poverty, inequality, and increased consumption of high calorie food: Experimental evidence for a causal link. Appetite, 100, 162-171. http: //dx.doi.org/10.1016/j.appet.2016.01.028

Callan, M.J., Ellard, J.H., Shead, N.W., \& Hodgins, D.C. (2008). Gambling as a search for justice: Examining the role of personal relative deprivation in gambling urges and gambling behavior. Personality and Social Psychology Bulletin, 34(11), 1514-1529. http://dx. doi.org/10.1177/0146167208322956

Callan, M.J., Kim, H., Gheorghiu, A.I., \& Matthews, W.J. (2017). The interrelations between social class, personal relative deprivation, and prosociality. Social Psychological and Personality Science, 8(6), 660-669. http://dx.doi.org/10.1177/1948550616673877

Callan, M.J., Kim, H., \& Matthews, W.J. (2015a). Predicting self-rated mental and physical health: The contributions of subjective socioeconomic status and personal relative deprivation. Frontiers in Psychology, 6. Article 1415. 1-14. http://dx.doi.org/10.3389/ fpsyg. 2015.01415

Callan, M.J., Kim, H., \& Matthews, W.J. (2015b). Age differences in social comparison tendency and Personal Relative Deprivation. Personality and Individual Differences, 87, 196-199. https://doi.org/10.1016/j. paid.2015.08.003

Cardel, M.I., Johnson, S.L., Beck, J., Dhurandhar, E., Keita, A.D., Tomczik, A.C., Pavela, G., Huo, T., Janicke, D.M., Muller, K., Piff, P.K., Peters, J.C., Hill, J.O., \& Allison, D.B. (2016). The effects of experimentally manipulated social status on acute eating behav- ior: A randomized, crossover pilot study, Physiology \& Behavior, 162, 93-101. https://doi.org/10.1016/ j.physbeh.2016.04.024

Cardel, M.I., Pavela, G., Janicke, D., Huo, T., Miller, D., Lee, A.M., Gurka, M.J., Dhurandhar, E., Peters, J.C., Caldwell, A.E., Krause, E., Fernandez, A., \& Allison, D.B. (2020). Experimentally manipulated low social status and food insecurity alter eating behavior among adolescents: A randomized control trial. Obesity, 28, 2010-2019. https://doi.org/10.1002/oby. 23002

Cheon, B.K., \& Hong, Y-Y. (2017). Mere experience of low subjective socioeconomic status stimulates appetite and food intake. Proceedings of the National Academy of Sciences, 114(1), 72-77. https://doi.org/10. 1073/pnas.1607330114

Drewnowski, A., \& Specter, S.E. (2004). Poverty and obseity: The role of energy density and energy costs. American Journal of Clinical Nutrition, 79(1), 6-16. https://doi.org/10.1093/ajcn/79.1.6

Epel, E.S., Tomiyama, A.J., Mason, A.E., Laraia, B.A., Hartman, W., Ready, K., Acree, M., Adam, T.C., St. Jeor, S., \& Kessler, D. (2014). The Reward-Based Eating Drive Scale: A self-report index of reward-based eating. PLoS ONE, 9(6). e101350. https://doi. org/10.1371/journal.pone.0101350

Gearhardt, A.N., Davis, C., Kuschner, R., \& Brownell, K.D. (2011). The addiction potential of hyperpalatable foods. Current Drug Abuse Reviews, 4, 140-145. https://doi.org/10.2174/1874473711104030140

Greitemeyer, T., \& Sagioglou, C. (2019). The impact of personal relative deprivation on aggression over time. Journal of Social Psychology, 159(6), 664675. https://doi.org/10.1080/00224545.2018. 1549013

Grotenhuis, M., Ben Pelzer, Eisinga, R., Nieuwenhuis, R., Schmidt-Catran, A., \& Konig, R. (2017). When size matters: advantages of weighted effect coding in observational studies. International Journal of Public Health, 62, 163-167. https://doi.org/10.1007/ s00038-016-0901-1

Keyes, O., Schmidt, D., Robinson, D., Davis, C., Rudis, B., Maxmind, Inc., Gloor, P. \& IP2Location.com (2020). rgeolocate: IP Address Geolocation. R package version 1.3.1. https://CRAN.R-project.org/ package $=$ rgeolocate

Kim, H., Callan, M.J., Gheorghiu, A.I., \& Matthews, W.J. (2017). Social comparison, personal relative deprivation, and materialism. British Journal of Social Psychology, 56, 373-392. https://doi.org/10.1111/ bjso. 12176

Maechler, M., Rousseeuw, P., Croux, C., Todorov, V., Ruckstuhl, A., Salibian-Barrera, M., Verbeke, T., Koller, M., Conceicao, E.L.T., \& di Palma, M.A. (2020). robustbase: Basic Robust Statistics. R package version 0.93-6. http://CRAN.R-project.org/ package=robustbase

Mason, A.E., Epel, E.S., Aschbacher, K., Lustig, R.H., Acree, M., Kristeller, J., Cohn, M., Dallman, M., Moran, P.J., Bacchetti, P., Laraia, B., Hecht, F.M., \& Daubenmier, J. (2016). Reduced reward-driven eating accounts for the impact of a mindfulness-based diet 
and exercise intervention on weight loss: Data from the SHINE randomized control trial. Appetite, 100(1), 86-93. https://doi.org/10.1016/j.appet.2016. 02.009

Matthews, W.J., Gheorghiu, A.I., \& Callan, M.J. (2016). Why do we overestimate others' willingness to pay? Judgment and Decision Making, 11(1), 21-39.

Mishra, S., \& Carleton, N. (2015). Subjective relative deprivation is associated with poorer physical and mental health. Social Science and Medicine, 147, 144149. https://doi.org/10.1016/j.socscimed. 2015.10.030

Mishra, S., \& Novakowski, D. (2016). Personal relative deprivation and risk: An examination of individual differecnes in personality, attitudes, and behavioural outcomes. Personality and Individual Differences, 90, 22-26. https://doi.org/10.1016/j.paid.2015. 10.031

Parker, R. N., \& Fenwick, R. (1983). The Pareto curve and its utility for open-ended income distributions in survey research. Social Forces, 61(3), 872--885.

Pavela, G., Lewis, D.W., Dawson, J.A., Cardel, M., \& Allison, D.B. (217). Social status and energy intake: A randomized control experiment. Clinical Obesity, 7, 316-322. https://doi.org/10.1111/cob.12198

R Core Team (2020). R: A language and environment for statistical computing. R Foundation for Statistical Computing, Vienna, Austria. Version 4.0.3. https: //www.R-project.org/

Revelle, W. (2020). psych: Procedures for personality and psychological research. R package version 2.0.12. https : //CRAN.R-project . org/package=psych

Rosenberg, M. (1965). Society and the adolescent selfimage. Princeton, NJ: Princeton University Press.

Signorell, A. et al. (2021). DescTools: Tools for descriptive statistics. R package version 0.99.40. https : //cran.r-project.org/package=DescTools

Sim, A.Y., Lim, E.X., Forde, C.G., \& Choen, B.K. (2018). Personal relative deprivation increases self-selected portion sizes and food intake. Appetite, 121(1), 268-274. https://doi.org/10.1016/j.appet.2017.11.100

Skylark, W.J., \& Baron-Cohen, S. (2017). Initial evidence that non-clinical autistic traits are asociated with lower income. Molecular Autism, 8, 61, 1-11. https:// doi.org/10.1186/s13229-017-0179-z

Skylark, W.J., Chan, K.T.F., Farmer, G.D, Gaskin, K.W., \& Miller, A.R. (2020). The delay-reward heuristic: What do people expect in intertemporal choice tasks? Judgment and Decision Making, 15(5), 611-629

Skylark, W.J., Farmer, G.D., \& Bahemia, N. (2021). Inference and prefernece in intertemporal choice. Judgment and Decision Making, 16(2), 422-459.

Smith, H.J., Pettigrew, T.F., Pippin, G.M., \& Bialosiewicz, S. (2012). Relative deprivation: A theoretical and meta-analytic review. Personality and Social Psychology Review, 16(3), 203-232. https: //doi.org/10.1177/1088868311430825

Smith, H.J., Ryan, D.A., Jaurique, A., \& Duffau, E. (2020). Personal relative deprivation and mental health among university students: Cross-sectional and longitudinal evidence. Analyses of Social Issues and Public
Policy, 20(1), 287-314. https://doi.org/10.1111/ asap. 12201

Tabir, N., Dupuis, D.R., Kim, H.S., \& Wohl, M.J.A. (2015). Economic mobility moderates the effect of relative deprivation on financial gambling motives and disordered gambling. International Gambling Studies, 15(2), 309-323. https://doi.org/10.1080/ 14459795.2015.1046468

Watson, D., Clark, L.A., \& Tellegen, A. (1988). Development and validation of brief measures of positive and negative affect: The PANAS scales. Journal of Personality and Social Psychology, 54(6), 1063-1070.

Wijayatunga, N.N., Ironuma, B., Dawson, J.A., Rusinovich, B., Myers, C.A., Cardel, M., Pavela, G., Martin, C.K., Allison, D.B., \& Dhurandhar, E.J. (2019). Subjective social status is asociated with compensation for large meals - A prospective pilot study. Appetite, 132, 249-256. https://doi.org/10.1016/ j.appet.2018.07.031

Zhang, H., Liu, M., \& Tian, Y. (2016). Individualbased relative deprivation (IRD) decreases prosocial behaviours. Motivation and Emotion, 40, 655-666. https://doi.org/10.1007/s11031-016-9564-8

Zoogah, D. B. (2010). Why should I be left behind? Employees' perceived relative deprivation and participation in development activities. Journal of Applied Psychology, 95(1), 159-173. https://doi.org/10.1037/ a0018019 


\section{Appendix}

Below we report the sample characteristics, correlation matrices, and regression coefficients for Studies 1 and 2 when participants whose IP address indicates that they were outside the US are included in the analyses. For Study 1 this extended sample comprised 198 males and 156 females; for Study 2 there were 453 males and 363 females.

Table 4: Sample characteristics (including non-US locations)

\begin{tabular}{|c|c|c|c|c|}
\hline & \multicolumn{4}{|c|}{ Study 1} \\
\hline & Min & Max & $M(S D)$ & $\alpha$ \\
\hline AGE & 18 & 83 & $37.84(13.56)$ & \\
\hline EDU & 1 & 4 & $2.79(0.69)$ & \\
\hline INC & 0.50 & 17.43 & $4.82(3.58)$ & \\
\hline ADJ & 0.10 & 12.50 & $2.33(1.83)$ & \\
\hline SSS & 1 & 10 & $4.72(1.81)$ & \\
\hline PRD & 1 & 6 & 3.21 (1.18) & .89 \\
\hline NEG & 1 & 4.30 & $1.54(0.68)$ & .94 \\
\hline \multirow[t]{3}{*}{ RED } & 1 & 5 & $2.26(0.98)$ & .93 \\
\hline & \multicolumn{4}{|c|}{ Study 2} \\
\hline & Min & $\operatorname{Max}$ & $M(S D)$ & $\alpha$ \\
\hline AGE & 19 & 75 & $36.37(11.42)$ & \\
\hline $\mathrm{EDU}$ & 1 & 4 & $2.71(0.67)$ & \\
\hline INC & 0.50 & 16.26 & $5.29(3.56)$ & \\
\hline ADJ & 0.08 & 10.5 & $2.50(1.70)$ & \\
\hline SSS & 1 & 9 & $4.62(1.75)$ & \\
\hline PRD & 1 & 6 & $3.21(1.08)$ & .85 \\
\hline $\mathrm{EST}$ & 1 & 4 & $2.98(0.67)$ & .94 \\
\hline RED & 1 & 5 & $2.28(0.97)$ & .93 \\
\hline
\end{tabular}

Abbreviations are the same as for Table 1 
Table 5: Study 1 Correlation Matrices (Data from all locations)

\begin{tabular}{|c|c|c|c|c|c|c|c|c|}
\hline \multirow[b]{3}{*}{ NEG } & \multicolumn{8}{|c|}{ Pearson correlations } \\
\hline & RED & NEG & PRD & SSS & ADJ & INC & $\mathrm{EDU}$ & AGE \\
\hline & $\begin{array}{c}.43(<.001) \\
{[.34, .51]}\end{array}$ & & & & & & & \\
\hline \multirow[t]{2}{*}{ PRD } & $.25(<.001)$ & $.39(<.001)$ & & & & & & \\
\hline & {$[.15, .35]$} & {$[.30, .48]$} & & & & & & \\
\hline \multirow[t]{2}{*}{ SSS } & $-.08(.144)$ & $-.19(<.001)$ & $-.49(<.001)$ & & & & & \\
\hline & {$[-.18, .03]$} & {$[-.29,-.08]$} & {$[-.57,-.41]$} & & & & & \\
\hline \multirow[t]{2}{*}{ ADJ } & $.01(.806)$ & $-.08(.133)$ & $-.28(<.001)$ & $.47(<.001)$ & & & & \\
\hline & {$[-.09, .12]$} & {$[-.18, .02]$} & {$[-.37,-.18]$} & {$[.38, .55]$} & & & & \\
\hline \multirow[t]{2}{*}{ INC } & $-.01(.857)$ & $-.08(.143)$ & $-.34(<.001)$ & $.51(<.001)$ & $.74(<.001)$ & & & \\
\hline & {$[-.11, .09]$} & {$[-.18, .03]$} & {$[-.43,-.24]$} & {$[.43, .59]$} & {$[.69, .79]$} & & & \\
\hline \multirow[t]{2}{*}{ EDU } & $-.05(.309)$ & $-.08(.129)$ & $-.19(<.001)$ & $.34(<.001)$ & $.36(<.001)$ & $.32(<.001)$ & & \\
\hline & {$[-.16, .05]$} & {$[-.18, .02]$} & {$[-.29,-.09]$} & {$[.24, .43]$} & {$[.27, .45]$} & {$[.23, .41]$} & & \\
\hline \multirow[t]{2}{*}{ AGE } & $-.25(<.001)$ & $-.22(<.001)$ & $-.18(.001)$ & $.10(.063)$ & $.10(.067)$ & $.05(.394)$ & $.14(.009)$ & \\
\hline & {$[-.35,-.15]$} & {$[-.32,-.12]$} & {$[-.28,-.07]$} & {$[-.01, .20]$} & {$[-.01, .20]$} & {$[-.06, .15]$} & {$[.04, .24]$} & \\
\hline \multirow[t]{4}{*}{ GEN } & $-.05(.373)$ & $.00(.955)$ & $.02(.767)$ & $-.09(.086)$ & $-.10(.073)$ & $-.08(.134)$ & $.00(.940)$ & $.17(.002)$ \\
\hline & {$[-.15, .06]$} & {$[-.10, .11]$} & {$[-.09, .12]$} & {$[-.19, .01]$} & {$[-.20, .01]$} & {$[-.18, .02]$} & {$[-.10, .11]$} & {$[.06, .27]$} \\
\hline & \multicolumn{8}{|c|}{ Kendall correlations } \\
\hline & RED & NEG & PRD & SSS & ADJ & INC & EDU & AGE \\
\hline NEG & $\begin{array}{c}.31(<.001) \\
{[.24, .37]}\end{array}$ & & & & & & & \\
\hline \multirow[t]{2}{*}{ PRD } & $.18(<.001)$ & $.31(<.001)$ & & & & & & \\
\hline & {$[.11, .26]$} & {$[.25, .38]$} & & & & & & \\
\hline \multirow[t]{2}{*}{ SSS } & $-.04(.260)$ & $-.16(<.001)$ & $-.38(<.001)$ & & & & & \\
\hline & {$[-.12, .04]$} & {$[-.23,-.08]$} & {$[-.44,-.31]$} & & & & & \\
\hline \multirow[t]{2}{*}{ ADJ } & $.04(.326)$ & $-.06(.091)$ & $-.23(<.001)$ & $.40(<.001)$ & & & & \\
\hline & {$[-.04, .11]$} & {$[-.14, .01]$} & {$[-.30,-.16]$} & {$[.34, .46]$} & & & & \\
\hline \multirow[t]{2}{*}{ INC } & $.02(.567)$ & $-.07(.071)$ & $-.25(<.001)$ & $.45(<.001)$ & $.62(<.001)$ & & & \\
\hline & {$[-.05, .10]$} & {$[-.14, .00]$} & {$[-.32,-.19]$} & {$[.38, .52]$} & {$[.57, .66]$} & & & \\
\hline \multirow[t]{2}{*}{ EDU } & $-.03(.538)$ & $-.05(.236)$ & $-.14(.001)$ & $.29(<.001)$ & $.29(<.001)$ & $.27(<.001)$ & & \\
\hline & {$[-.11, .05]$} & {$[-.14, .03]$} & {$[-.22,-.06]$} & {$[.21, .37]$} & {$[.22, .37]$} & {$[.19, .35]$} & & \\
\hline \multirow[t]{2}{*}{ AGE } & $-.17(<.001)$ & $-.18(<.001)$ & $-.10(.006)$ & $.06(.137)$ & $.08(.023)$ & $.04(.274)$ & $.11(.009)$ & \\
\hline & {$[-.24,-.10]$} & {$[-.26,-.11]$} & {$[-.17,-.03]$} & {$[-.02, .13]$} & {$[.01, .15]$} & {$[-.03, .11]$} & {$[.02, .19]$} & \\
\hline \multirow[t]{2}{*}{ GEN } & $-.05(.218)$ & $.04(.387)$ & $.00(.942)$ & $-.07(.137)$ & $-.07(.094)$ & $-.07(.105)$ & $.01(.819)$ & $.14(.001)$ \\
\hline & {$[-.14, .03]$} & {$[-.05, .13]$} & {$[-.09, .09]$} & {$[-.16, .02]$} & {$[-.16, .01]$} & {$[-.16, .02]$} & {$[-.09, .11]$} & {$[.06, .22]$} \\
\hline
\end{tabular}

$p$-values are shown in parentheses; the $95 \% \mathrm{CI}$ is shown below each estimate. GEN = Gender; other abbreviations are the same as for Table 1 . 
Table 6: Study 2 Correlation Matrices (Data from all locations)

\begin{tabular}{|c|c|c|c|c|c|c|c|c|}
\hline \multirow{4}{*}{ EST } & \multicolumn{8}{|c|}{ Pearson correlations } \\
\hline & RED & $\mathrm{EST}$ & PRD & SSS & ADJ & INC & $\mathrm{EDU}$ & AGE \\
\hline & $-.29(<.001)$ & & & & & & & \\
\hline & {$[-.35,-.22]$} & & & & & & & \\
\hline \multirow[t]{2}{*}{ PRD } & $.18(<.001)$ & $-.54(<.001)$ & & & & & & \\
\hline & {$[.11, .25]$} & {$[-.59,-.49]$} & & & & & & \\
\hline \multirow[t]{2}{*}{ SSS } & $-.04(.306)$ & $.38(<.001)$ & $-.46(<.001)$ & & & & & \\
\hline & {$[-.10, .03]$} & {$[.32, .44]$} & {$[-.52,-.41]$} & & & & & \\
\hline \multirow[t]{2}{*}{ ADJ } & $-.04(.242)$ & $.20(<.001)$ & $-.25(<.001)$ & $.52(<.001)$ & & & & \\
\hline & {$[-.11, .03]$} & {$[.14, .27]$} & {$[-.32,-.19]$} & {$[.46, .56]$} & & & & \\
\hline \multirow[t]{2}{*}{ INC } & $-.02(.618)$ & $.25(<.001)$ & $-.33(<.001)$ & $.61(<.001)$ & $.72(<.001)$ & & & \\
\hline & {$[-.09, .05]$} & {$[.19, .32]$} & {$[-.39,-.27]$} & {$[.56, .65]$} & {$[.68, .75]$} & & & \\
\hline \multirow[t]{2}{*}{ EDU } & $.02(.587)$ & $.13(<.001)$ & $-.13(<.001)$ & $.39(<.001)$ & $.32(<.001)$ & $.32(<.001)$ & & \\
\hline & {$[-.05, .09]$} & {$[.06, .19]$} & {$[-.19,-.06]$} & {$[.33, .45]$} & {$[.26, .38]$} & {$[.25, .38]$} & & \\
\hline \multirow[t]{2}{*}{ AGE } & $-.15(<.001)$ & $.17(<.001)$ & $-.11(.002)$ & $.06(.090)$ & $.11(.002)$ & $.08(.016)$ & $.05(.157)$ & \\
\hline & {$[-.22,-.08]$} & {$[.11, .24]$} & {$[-.18,-.04]$} & {$[-.01, .13]$} & {$[.04, .18]$} & {$[.02, .15]$} & {$[-.02, .12]$} & \\
\hline \multirow[t]{4}{*}{ GEN } & $.09(.014)$ & $-.03(.397)$ & $-.03(.421)$ & $.00(.935)$ & $-.07(.046)$ & $.02(.628)$ & $-.01(.806)$ & $.14(<.001)$ \\
\hline & {$[.02, .15]$} & {$[-.10, .04]$} & {$[-.10, .04]$} & {$[-.07, .07]$} & {$[-.14,-.00]$} & {$[-.05, .09]$} & {$[-.08, .06]$} & {$[.07, .20]$} \\
\hline & \multicolumn{8}{|c|}{ Kendall correlations } \\
\hline & RED & $\mathrm{EST}$ & PRD & SSS & ADJ & INC & EDU & AGE \\
\hline \multirow[t]{2}{*}{ EST } & $-.22(<.001)$ & & & & & & & \\
\hline & {$[-.27,-.17]$} & & & & & & & \\
\hline \multirow[t]{2}{*}{ PRD } & $.14(<.001)$ & $-.40(<.001)$ & & & & & & \\
\hline & {$[.09, .19]$} & {$[-.45,-.36]$} & & & & & & \\
\hline \multirow[t]{2}{*}{ SSS } & $-.00(.965)$ & $.27(<.001)$ & $-.35(<.001)$ & & & & & \\
\hline & {$[-.05, .05]$} & {$[.22, .32]$} & {$[-.40,-.31]$} & & & & & \\
\hline \multirow[t]{2}{*}{ ADJ } & $-.03(.171)$ & $.16(<.001)$ & $-.19(<.001)$ & $.41(<.001)$ & & & & \\
\hline & {$[-.08, .02]$} & {$[.12, .21]$} & {$[-.23,-.14]$} & {$[.36, .45]$} & & & & \\
\hline \multirow[t]{2}{*}{ INC } & $-.01(.579)$ & $.20(<.001)$ & $-.24(<.001)$ & $.50(<.001)$ & $.61(<.001)$ & & & \\
\hline & {$[-.06, .04]$} & {$[.15, .24]$} & {$[-.28,-.19]$} & {$[.46, .54]$} & {$[.58, .64]$} & & & \\
\hline \multirow[t]{2}{*}{ EDU } & $.03(.322)$ & $.10(.001)$ & $-.11(<.001)$ & $.33(<.001)$ & $.27(<.001)$ & $.26(<.001)$ & & \\
\hline & {$[-.03, .08]$} & {$[.04, .15]$} & {$[-.16,-.05]$} & {$[.28, .38]$} & {$[.22, .32]$} & {$[.21, .32]$} & & \\
\hline \multirow[t]{2}{*}{ AGE } & $-.10(<.001)$ & $.12(<.001)$ & $-.07(.003)$ & $.05(.059)$ & $.12(<.001)$ & $.10(<.001)$ & $.06(.034)$ & \\
\hline & {$[-.14,-.05]$} & {$[.07, .16]$} & {$[-.12,-.03]$} & {$[-.00, .10]$} & {$[.07, .17]$} & {$[.05, .15]$} & {$[.01, .11]$} & \\
\hline \multirow[t]{2}{*}{ GEN } & $.05(.064)$ & $-.03(.367)$ & $-.02(.440)$ & $-.00(.876)$ & $-.06(.044)$ & $.01(.776)$ & $-.00(.935)$ & $.10(<.001)$ \\
\hline & {$[-.00, .11]$} & {$[-.08, .03]$} & {$[-.08, .04]$} & {$[-.06, .06]$} & {$[-.11,-.00]$} & {$[-.05, .07]$} & {$[-.07, .06]$} & {$[.05, .16]$} \\
\hline
\end{tabular}

$p$-values are shown in parentheses; the $95 \% \mathrm{CI}$ is shown below each estimate. GEN = Gender; other abbreviations are the same as for Table 1 . 
Study 1: All Locations (OLS)

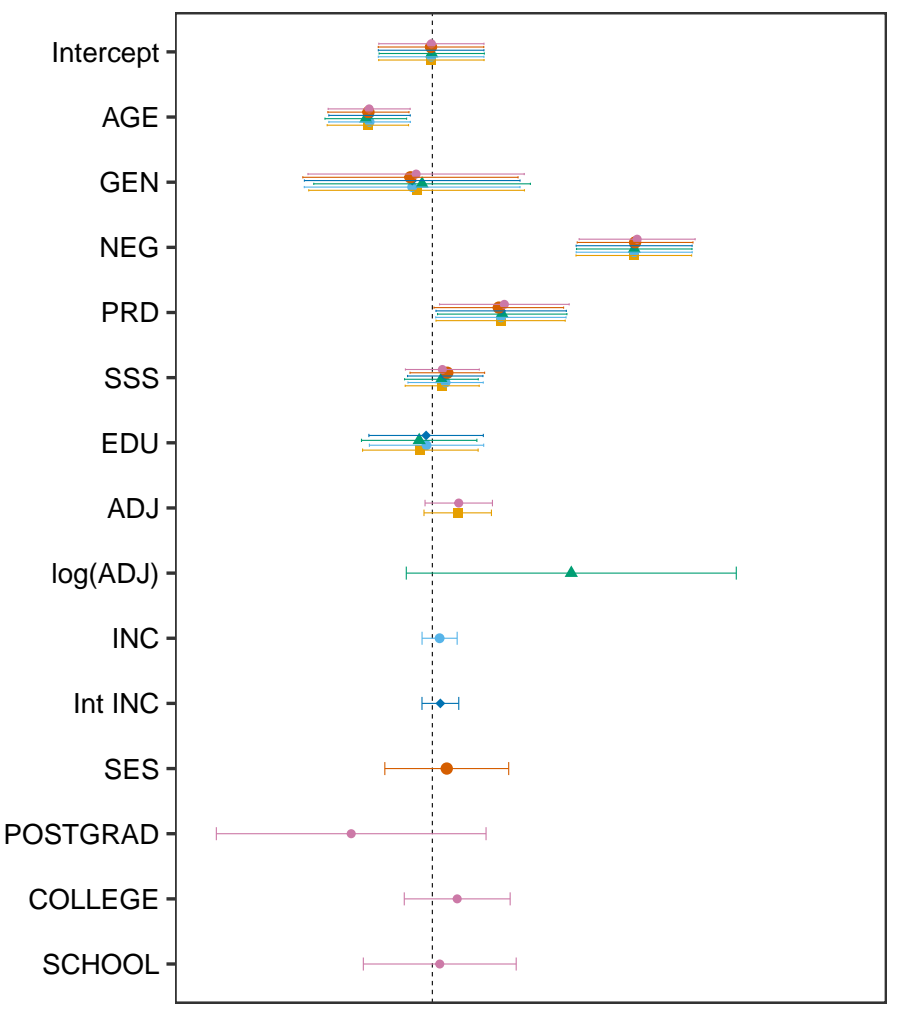

Study 2: All Locations (OLS)

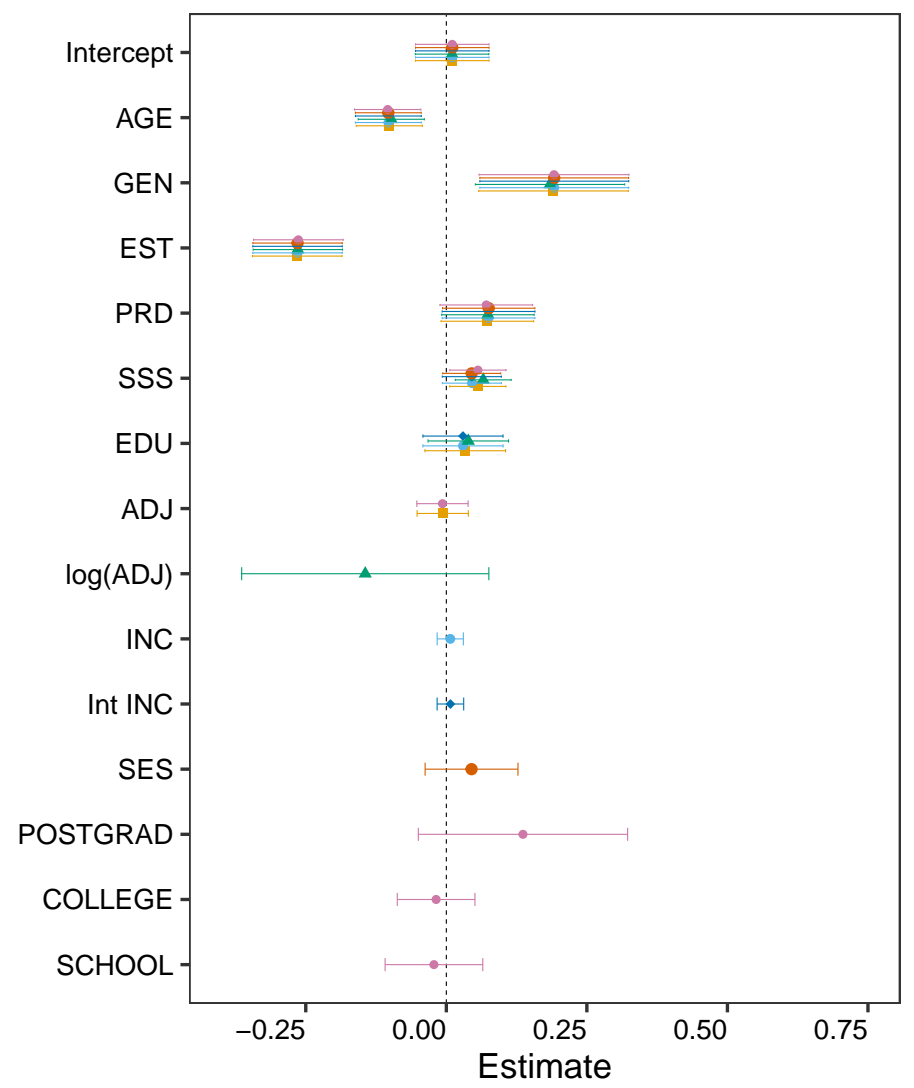

Study 1: All Locations (Robust)

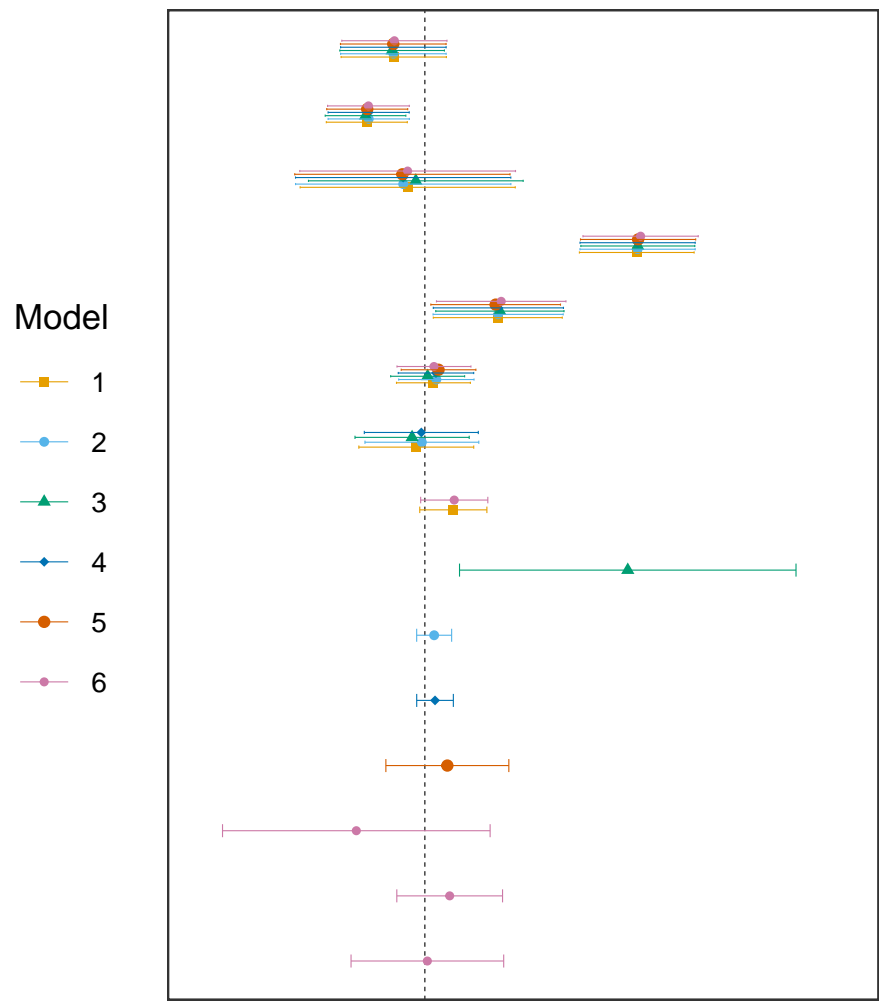

Study 2: All Locations (Robust)

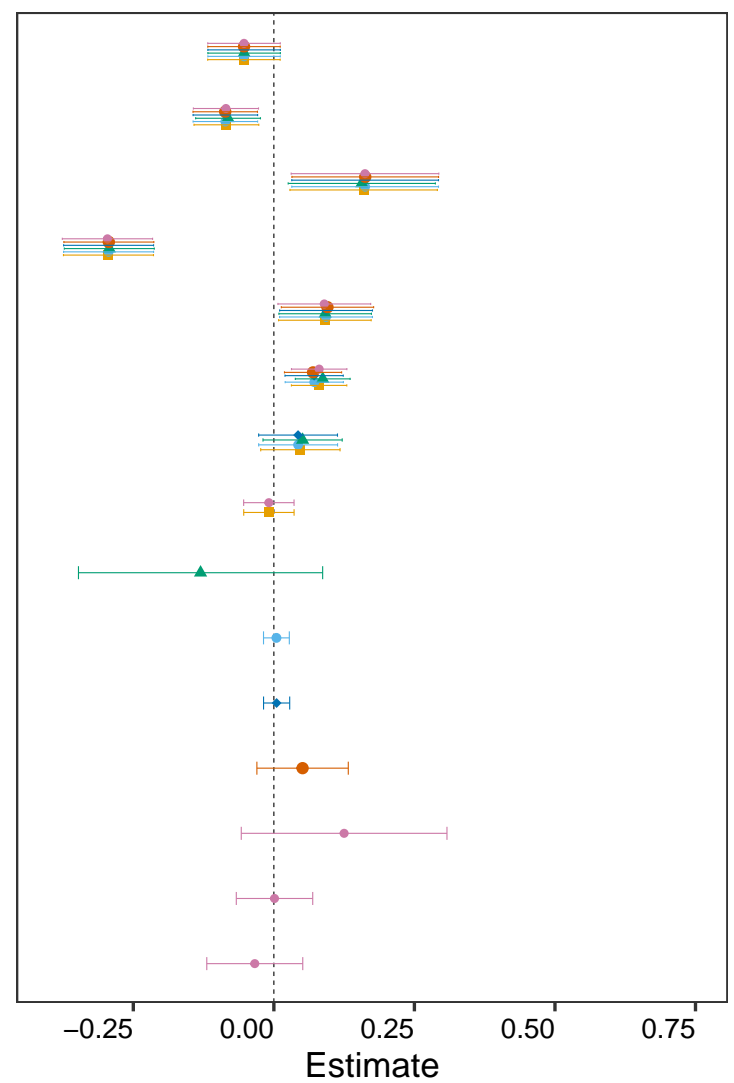

Figure 2: Regression coefficients when data from non-US locations are included. See main text for explanation of the predictor abbreviations and models. 